Research Article

\title{
Experimental Study on Seismic Performance of Prefabricated Utility Tunnel
}

\author{
Xu Duan ${ }^{1},{ }^{1}$ Qi Dong, ${ }^{2,3}$ and Wanjun Ye ${ }^{1}$ \\ ${ }^{1}$ School of Architectural and Civil Engineering, Xi'an University of Science and Technology, Xi'an, Shaanxi 710054, China \\ ${ }^{2}$ Shaanxi Science \& Technology Holding Group Co., Ltd., Xi'an, Shaanxi 710054, China \\ ${ }^{3}$ State Key Laboratory for Strength and Vibration of Mechanical Structures, Xi'an Jiaotong University, Xi'an 710049, China
}

Correspondence should be addressed to Xu Duan; duanxu@xust.edu.cn

Received 7 July 2019; Revised 15 September 2019; Accepted 23 September 2019; Published 27 October 2019

Academic Editor: Hossein Moayedi

Copyright (c) $2019 \mathrm{Xu}$ Duan et al. This is an open access article distributed under the Creative Commons Attribution License, which permits unrestricted use, distribution, and reproduction in any medium, provided the original work is properly cited.

\begin{abstract}
Utility tunnel is a kind of underground tunnel structure that carries more than two types of public utility lines, and the utility tunnels built by the prefabricated method have been adopted in many modern cities due to their easy maintenance and environmental protection capabilities. However, knowledge about the seismic performance of the prefabricated utility tunnel and pipelines inside is quite limited. In this paper, a prefabricated utility tunnel newly built in Xi'an, China, is taken as the prototype; a series of shaking table tests are conducted to investigate the seismic performance of the prefabricated utility tunnel in loess foundation, using El Centro earthquake wave as the input loading. Details of the experimental setup focus on the design of the soil container, scaled model $(1: 10)$, sensor arrangement, and test cases. Dynamic responses including evaluation of boundary effect, the amplification factor of the ground and structure, distribution of soil pressure, characteristics of predominant frequencies, and the damage phenomena are analyzed. Dynamic strain obtained by Fiber Bragg Grating sensors releases the critical positions of the prefabricated utility tunnel during the earthquake. Moreover, the dynamic responses of the pipelines contained in the utility tunnel are also analyzed. From aforementioned results, the seismic performance of the prefabricated utility tunnel has been revealed. The results will provide a reference for the seismic design of prefabricated utility tunnels.
\end{abstract}

\section{Introduction}

With urbanization advancement speeding up around the world, the utilization of underground space has been concerned. Intensive underground utility pipes make urban underground space chaotic, and the maintenance of pipelines is inconvenient and costly due to the excavation. In past decades, utility tunnel is an effective method to solve aforementioned problems. It is a kind of underground structure similar to a shallow tunnel, which can hold kinds of utilities collectively, and there is sufficient space for daily maintenance and emergency repair without the need for excavation. Furthermore, the prefabrication technique has been adopted in construction due to the faster construction speed and the high level of standardization, and it has become the trend of modern city construction.
The earliest utility tunnel was built in Paris in 1833, which contained water supply pipes, electric power, and telephone cables. This advanced lifeline system supports the development of Paris up to now [1]. After that, the utility tunnel started to be adopted in many European countries, such as Britain, German, and Spain. The first utility tunnel built in Asia was a trail project in the reconstruction of Tokyo after the earthquake. Also, the "Guideline for Construction of Utility Tunnel" published by the Japanese government effectively promoted the construction of utility tunnel in Japan. Until now, the total length of the utility tunnel in Japan has reached to $2500 \mathrm{~km}$ until 2017; note that the prefabricated method has been widely used due to the faster construction speed and higher quality. In China, chaotic underground pipelines have been plaguing the development of many cities for years, and accidents often occur 
due to the failure of chaotic underground pipelines [2]. In the past decade, the utility tunnel has been adopted to be the fundamental method to solve the problems of urban lifeline system in China. Until 2018, the total length of the utility tunnel under construction has reached $2000 \mathrm{~km}$ with encouragement from local governments. Prefabricated utility tunnel has been adopted in Shanghai, Xi'an, Xiamen, and other cities, and practical experience indicates that the period of utility tunnel construction could be shortened by $45 \%$ with the prefabricating techniques [3]. Furthermore, due to its green and cost benefits, prefabricated construction has become the trend of construction in China $[4,5]$.

Utility tunnels are usually shallow buried and built by the cut-and-over method. Experience from earthquake destruction shows that the underground structure built by this method would be vulnerable in earthquake, and the seismic design for such structure is necessary [6]. As far as the utility tunnel is concerned, the most violent seismic damage of the utility tunnel system occurred in Japan, in the HyogokenNambu earthquake in 1995. During this violent earthquake, almost all the utility tunnels near the epicenter were damaged, and several types of damage were found out [7-9], cracks appeared around all the inside corners of the No. 2 Kobe utility tunnel, and cut-through cracks on the middle column were found at the lower layer. Moreover, the deformation of surrounding soil led to the disconnection and stagger of tunnel joints. After earthquake, the repairment and reinforcement of the utility tunnel are difficult and costly, so it is necessary to assess the seismic response of utility tunnels and try to retain them functional in earthquake disaster. Especially in China, current design codes for underground structures have not covered seismic design of the utility tunnel, but the construction is continuously increasing in earthquake-prone areas.

Over the past decades, numerous efforts have been made to investigate the seismic performance of utility tunnels. The typical failure modes of utility tunnels have been summarized by fieldwork [9], and it is of high value for researches of the utility tunnel's seismic design. A simplified model was proposed by Nishioka and Unjoh [10] to evaluate the seismic performance of a utility tunnel. A quasi-static experimental study showed that the wall slab joint of the utility tunnel is relatively week under shear force, and measures to enhance utility tunnel's shear capacity and ductility have been proposed [11]. Through numerical simulation, it was found that the deformation pattern of the utility tunnel is global bending under shear wave excitation [12]. Moreover, seismic response of rectangular tunnels can also be used as a reference; Tsinidis [13] investigated the dynamic characteristics of rectangular tunnels with various cross sections by the numerical simulation method, and the salient parameters which could affect tunnel's dynamic performance have been carried out.

As far as the seismic risk of the utility tunnel is concerned, the method of shaking table test has been used to investigate the seismic response and damage mechanisms of the cast-in-place utility tunnel. Through shaking table tests, the dynamic responses of utility tunnels which have a single span and double-span cross section have been carried out, respectively [14]. Based on the shaking table test and numerical simulation, the failure criterion and seismic reliability of the utility tunnel were analyzed by Yue and Li [15]. Chen et al. [16] researched the effect of nonuniform excitation on the utility tunnel by a unique shaking table system. However, up to now, most research on seismic response of the utility tunnel focuses on the utility tunnel with the cast-in-place method. Experimental research on seismic response of the prefabricated utility tunnel is still limited.

In this paper, a scaled model $(1: 10)$ of the prefabricated utility tunnel was carried out, and the pipelines inside were also considered. A series of shaking table tests were conducted using El Centro earthquake waves of different PGA $(0.125 \mathrm{~g}$ to $0.75 \mathrm{~g})$ as the input loading. The detailed description of the experimental setup is provided, which consists of the soil container, similarity relation, instrumentation, and test case. The seismic responses of the soil-structure system were obtained in the shaking table test, focusing on the acceleration, earth pressure, interaction between the tunnel model and surrounding soil, and the structural strain. Cracks of the utility tunnel and the failure of pipelines inside were examined. Based on the experimental investigation, the seismic performances of the prefabricated utility tunnel and pipelines inside have been determined, and recommendations are carried out as the reference for seismic design and construction of the prefabricated utility tunnel.

\section{Experimental Setup}

2.1. Shaking Table. The shaking table test was conducted in the vibration laboratory in China Electronics Technology Group Corporation (CETC), using an electromagnetic shaking table manufactured by Dongling company. The testing system, which consisted of a shaking table, loading control, and data acquisition, has been reformed by the lab of CETC. The dimension of the shaking table is $1.5 \mathrm{~m} \times 1.5 \mathrm{~m}$ in plane, and the shaking table can be input with two-dimensional and four-degree-of-freedom motions. The working frequency ranges from $0.1 \mathrm{~Hz}$ to $2500 \mathrm{~Hz}$, the maximum acceleration in each direction can reach $10 \mathrm{~g}$, and the maximum load capacity is $1500 \mathrm{~kg}$.

2.2. Model Soil Container. Design of a model soil container is an important part of the shaking table test, which could influence the boundary condition in the test. To minimize the boundary effect in shaking table tests, design of the soil container has been developed in past decades which can be divided into two categories: flexible soil container and rigid container with the absorbing material. The laminar box is a kind of flexible soil container which is designed based on equivalent shear beam approach. However, weight of the laminar box exceeds the load limit of the shaking table used in this test. So, a rigid model soil container made of square steel and organic glass was designed to contain the model soil, as shown in Figure 1. The soil container had the dimensions of $1.3 \mathrm{~m}$ long $(x), 1.3 \mathrm{~m}$ wide $(y)$, and $1.3 \mathrm{~m}$ 


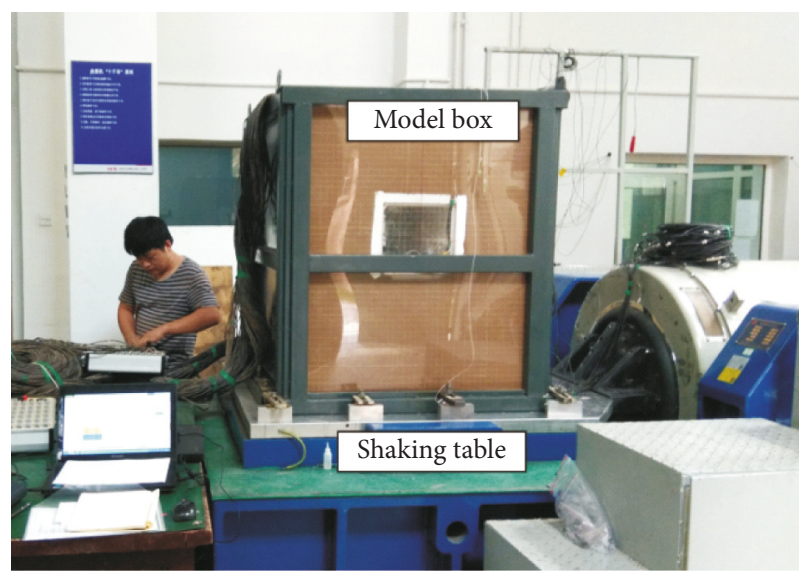

FIgURE 1: Shaking table system and the soil container.

high $(z)$. To minimize the boundary effect, EPE foam panels were put on the inner sides of end walls of the soil container. Thickness of the foam panels was set to $30 \mathrm{~mm}$. The density of the foam is $24 \mathrm{~kg} / \mathrm{m}^{3}$ and Young's modulus is $39 \mathrm{kPa}$. The absorbing material could reduce the boundary effect of the rigid model box [17]. Furthermore, gravels with the diameter of $5 \mathrm{~cm}$ were fixed on the bottom of the soil container to enhance the friction between soil and the bottom of the container.

2.3. Sensors and Data Acquisition System. In this test, three kinds of sensors were utilized to assess the dynamic response of the utility tunnel, including an accelerometer, soil pressure gauge, and Fiber Bragg Grating sensor (FBG sensor). The acceleration sensor used in this test is ST100T conducted by Dongling company. The working frequency is between 0.2 and $15000 \mathrm{~Hz}$, and the sensitivity is $100 \mathrm{mv} / \mathrm{g}$. The outside diameter of the soil pressure gauge is $30 \mathrm{~mm}$, the capacity is $150 \mathrm{kPa}$, and the precision is $0.5 \%$ of full scale. Fiber Bragg Grating Sensors are provided by the Laboratory of Information Photonics Technology of Xi'an Jiao Tong University; the maximum acquisition rate is $5000 \mathrm{~Hz}$, the capacity is $1500 \mu \varepsilon$, and the precision is $0.1 \mu \varepsilon$. The data acquisition system with 128 channels is produced by MTS Company, the sampling rate can reach to $5000 \mathrm{~Hz}$; in this test, it was set to $1000 \mathrm{~Hz}$.

\section{Test Design}

3.1. Similarity Relationships. According to the similarity theory, geometric similarity should be considered primarily. Considering the capacity of the shaking table, size of the soil container, and the convenience of manufacturing, the scale factor of geometric is set to 0.1. In this test, the model structure was composed of plaster. The characteristics of plaster such as good homogeneity and low elastic modulus provide the flexibility to the design of the similarity relationship. By adjusting the ratio of water and sand in plaster, the similarity relationships of elastic modulus and density were determined and other similarity relationships deduced by the Buckingham $\pi$ law. The similarity laws of the shaking table test are summarized in Table 1.

3.2. Model Structure and Model Soil. The prototype of the shaking table test is a newly-built prefabricated utility tunnel in Xi'an, China, which is composed of reinforced concrete in the grade of $\mathrm{C} 40$. It has a single span with the square cross section of $3 \mathrm{~m} \times 3 \mathrm{~m}$, and all the walls of the utility tunnel are identical at $30 \mathrm{~cm}$ of thickness. The length of each prefabricated segment is $2 \mathrm{~m}$ and all of them are connected with longitudinal joints, and rubber layers are installed in the joints between each segment. HPB300 is used as the reinforcement in the utility tunnel. In addition, various pipes are installed in the prototype tunnel, including water pipes, electricity pipes, and gas pipes.

According to the similarity relationships, the utility tunnel model was manufactured with the geometrical scale of $1: 10$. As shown in Figure 2, the process of manufacture includes three parts: making reinforcement cage model, pouring with PVC formwork, and assembling of segments with joints and the rubber layers. The material of the reinforcement cage model and the joint bolt is 6061 aluminum. The diameters are $4 \mathrm{~mm}$ and $6 \mathrm{~mm}$, respectively, due to the similarity relationship. In addition, models of electricity pipe and gas pipe were installed on the side wall and the floor of the tunnel, respectively; the structure model after assembling and pipe installation is shown in Figure 3.

The model soil chosen from the field foundation of the prototype project was placed into the soil container layer by layer. Each layer was compacted to $10 \mathrm{~cm}$ in thickness and ensured the uniformity of density. The model soil after compaction in container was tested on a triaxial test system, and its properties are shown in Table 2. To simulate the practical condition, the construction of the model tunnel was also similar to the actual construction with the cut-cover method. After excavation, the model tunnel was placed to the predetermined position and then assembled. Finally, model soil was filled upon the tunnel, the buried depth was set to $30 \mathrm{~cm}$ (the prototype is $3 \mathrm{~m}$ ).

3.3. Sensor Arrangement. The arrangement of 22 accelerometers (ACC), 14 soil pressure gauges, and 14 FBG sensors are illustrated in Figures 4-6, respectively. As shown in Figure 4, ACC A0 is set on the shaking table to record the input wave during the test. ACC A5, A7, A9, A11, and A13 are set to investigate the propagation of seismic waves in model soil; ACC A6, A8, A10, A12, and A14 are set as the parallel lines relatively far away from the structure. ACC A3, A13, and A14 and A2, A5, and A6 are set to analyse the boundary effect in shallow and deep position of model soil, respectively. ACC As1-As5 and As6 and As7 are set to record the seismic response of the utility tunnel model and pipeline models. As shown in Figure 5, soil pressure gauges S1-S6 and Ss1-Ss3 were set to explore the distribution of the dynamic earth pressure and the dynamic interaction between structure and soil, respectively. In addition, FBG sensors F1-F8 and F9-F14 were linearly arranged at the inner side of the model structure 
TABLE 1: Similarity laws of the model structure.

\begin{tabular}{lccc}
\hline Item & Physical parameters & Similarity relation & Ratio of similarity \\
\hline \multirow{2}{*}{ Geometry relation } & Length & $\lambda_{\mathrm{L}}$ & $1 / 10$ \\
& Displacement & $\lambda_{\mathrm{l}}$ & $1 / 10$ \\
\hline \multirow{3}{*}{ Material relation } & Strain & $\lambda_{\varepsilon}$ & 1 \\
& Stress & $\lambda_{\sigma}=\lambda_{\mathrm{E}} \lambda_{\varepsilon}$ & $1 / 4$ \\
& Elastic modulus & $\lambda_{\mathrm{E}}$ & $1 / 4$ \\
& Density & $\lambda_{\rho}$ & $10 / 4$ \\
Dynamic relation & Time & $\lambda_{\mathrm{t}}=\sqrt{\lambda_{\mathrm{L}} / \lambda_{\mathrm{a}}}$ & $\sqrt{1 / 10}$ \\
& Frequency & $\lambda_{\mathrm{f}}=\sqrt{\lambda_{\mathrm{L}} / \lambda_{\mathrm{a}}}$ & $\sqrt{10}$ \\
& Acceleration & $\lambda_{\mathrm{a}}$ & 1 \\
\hline
\end{tabular}

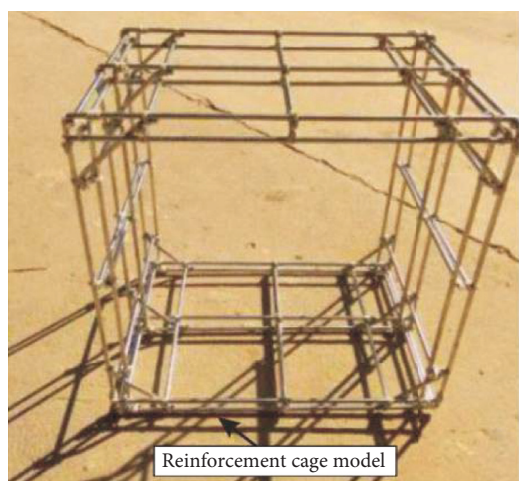

(a)

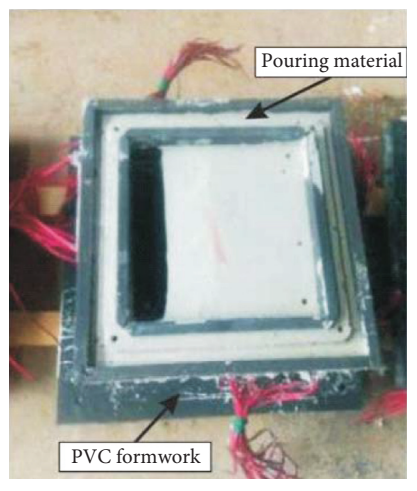

(b)

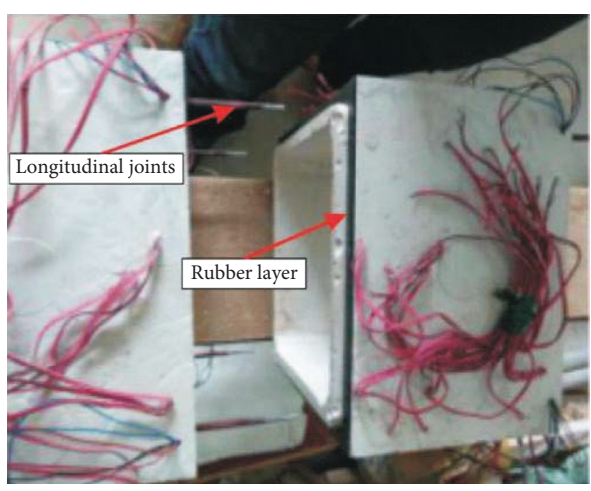

(c)

Figure 2: Manufacture of the utility tunnel model: (a) reinforcement cage model; (b) pouring of segment; (c) assembling of segments.

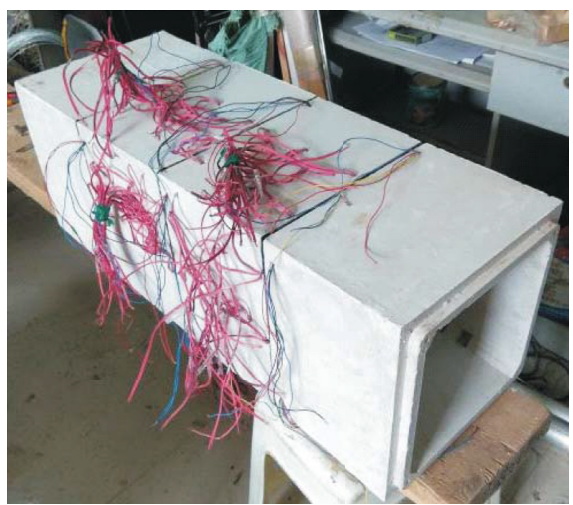

(a)

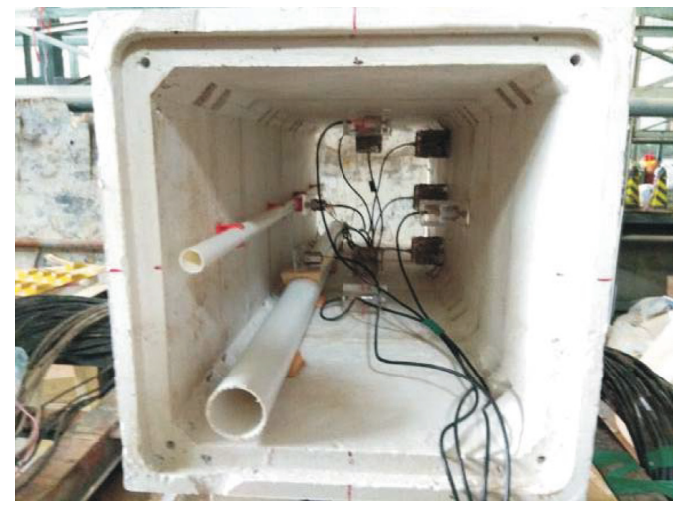

(b)

FIGURE 3: Model structure: (a) prefabricated utility tunnel model; (b) pipeline model hold by the tunnel.

TABle 2: Physical properties of model soil.

\begin{tabular}{lcccc}
\hline & Density $\left(\mathrm{kN} / \mathrm{m}^{3}\right)$ & Water content $(\%)$ & Cohesion strength $(\mathrm{kPa})$ & Friction angle $\left(^{\circ}\right)$ \\
\hline Prototype soil & 17.9 & 20.00 & 26.00 & 22.00 \\
Model soil & 16.2 & 16.56 & 17.68 & 14.60 \\
\hline
\end{tabular}

to record the dynamic strain; the cross-sectional arrangement and longitudinal arrangement are shown in Figures 6(a) and 6(b), respectively.
3.4. Test Cases. To explore the seismic response of the utility tunnel, the El Centro earthquake acceleration record (N-S component) was selected as the prototype earthquake 


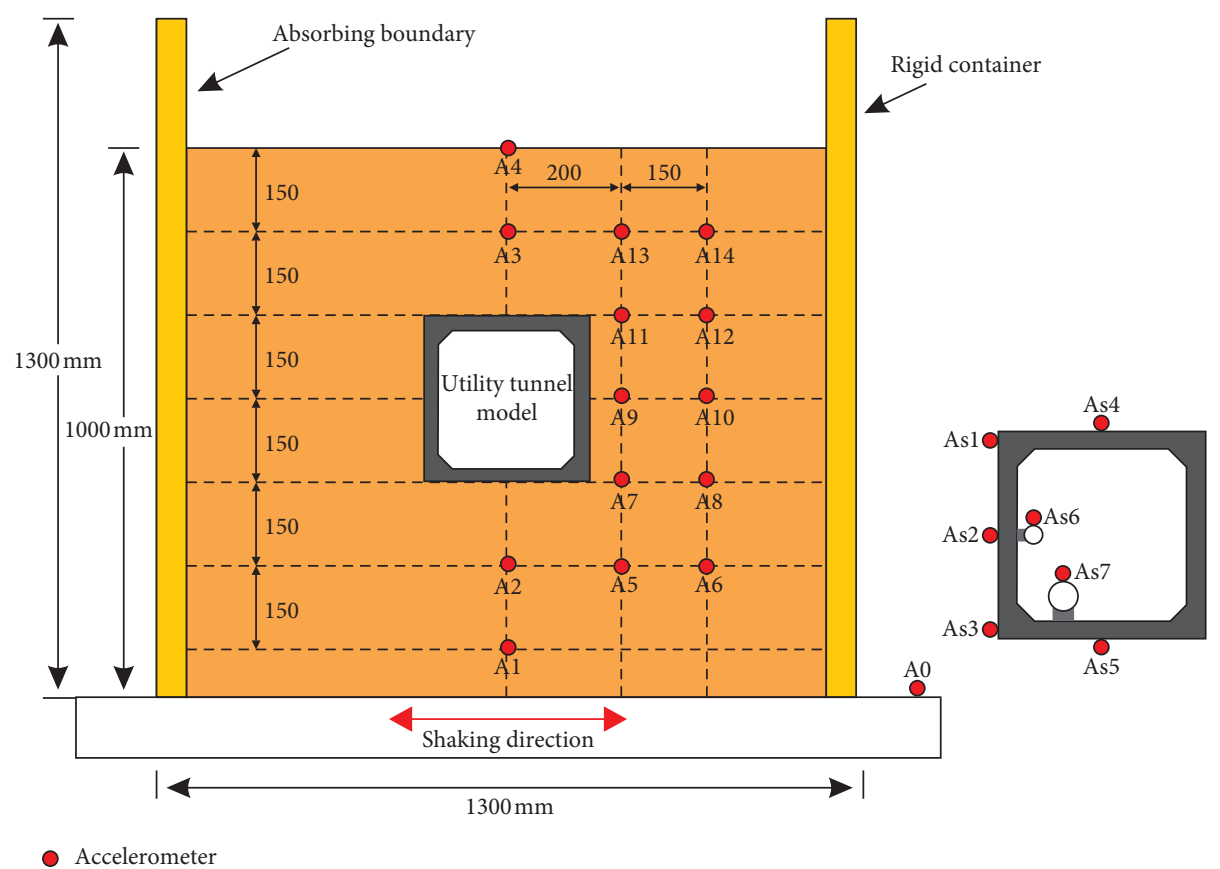

Figure 4: Arrangement of accelerometers embedded in the soil and structure.

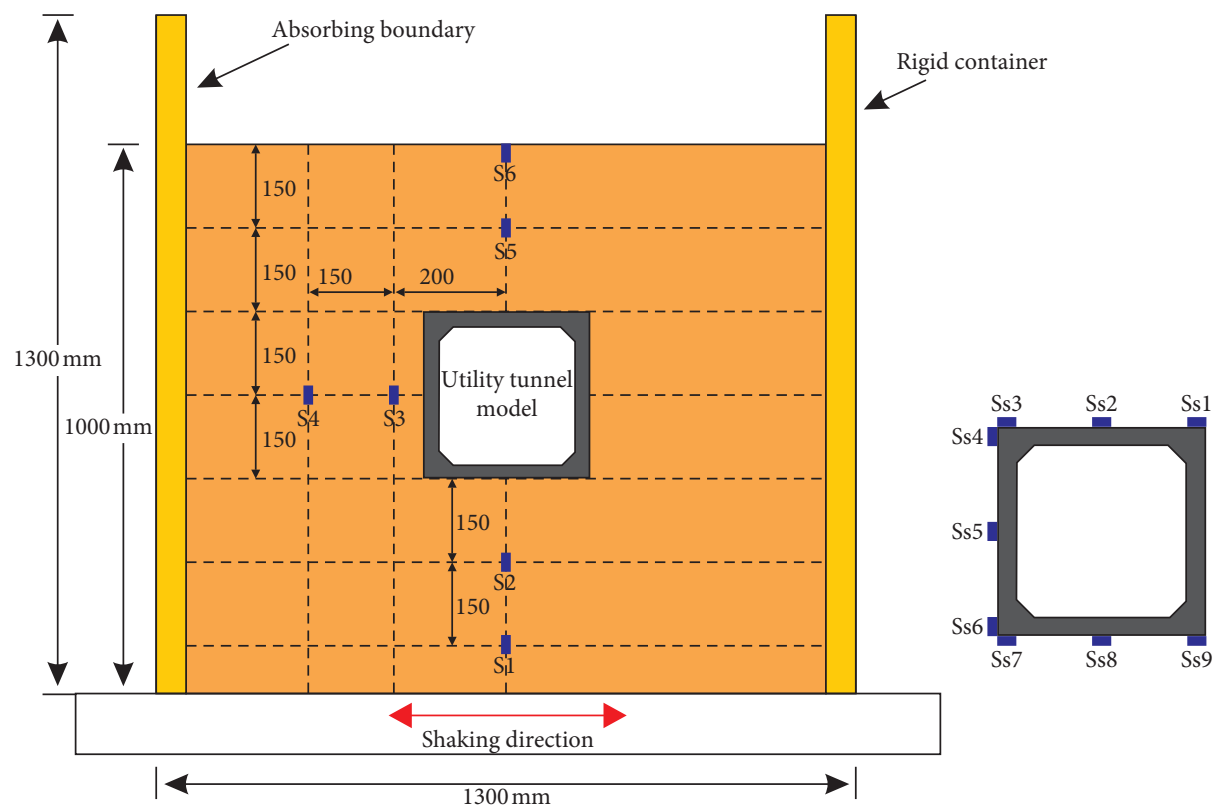

- Soil pressure gauge

FIgURE 5: Arrangement of soil pressure gauge embedded in the soil and structure.

excitation, as shown in Figure 7. According to the scaled factor for time, the duration of the earthquake was uniformly compressed to $1 / 4$. And, the peak acceleration of the seismic wave was adopted by the following formula:

$$
A^{\prime}(t)=\left(\frac{A_{\max }^{\prime}}{A_{\max }}\right) A(t),
$$

where $A(t)$ and $A_{\max }$ are the time history and peak acceleration of the prototype wave and $A^{\prime}(t)$ and $A_{\max }^{\prime}$ are the time history and peak acceleration of the adopted wave in the test. According to the code for seismic design for underground structure in China (GB50111-2006), the peak ground acceleration (PGA) in this test was adjusted to $0.125 \mathrm{~g}, 0.25 \mathrm{~g}, 0.375 \mathrm{~g}, 0.5 \mathrm{~g}$, and $0.75 \mathrm{~g}$. In addition, in order to explore the fundamental frequency of the structure-soil system, white noise was performed for $20 \mathrm{~s}$ in each case. A total of 11 cases are arranged in this shaking table test, as shown in Table 3. 


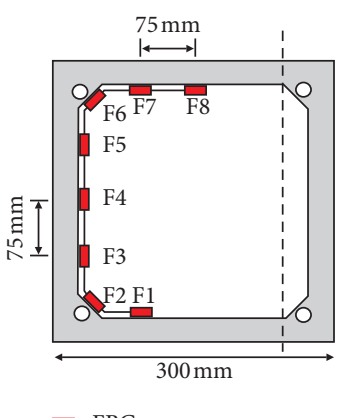

(a)

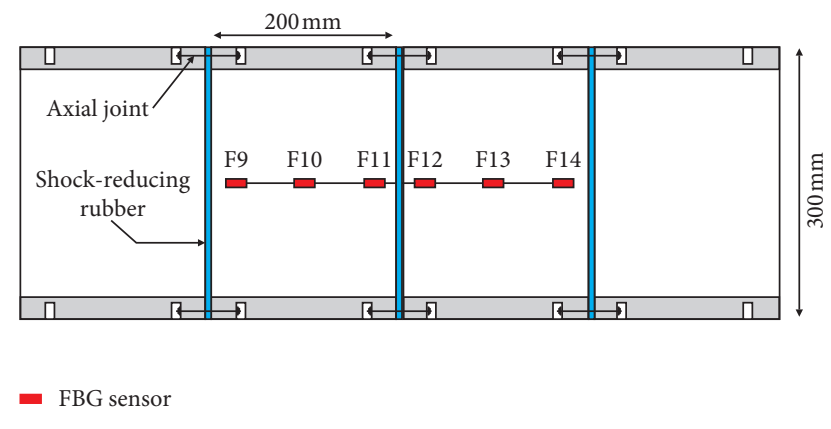

(b)

FIGURE 6: Arrangement of the FBG sensors: (a) cross-section arrangement; (b) longitudinal arrangement.

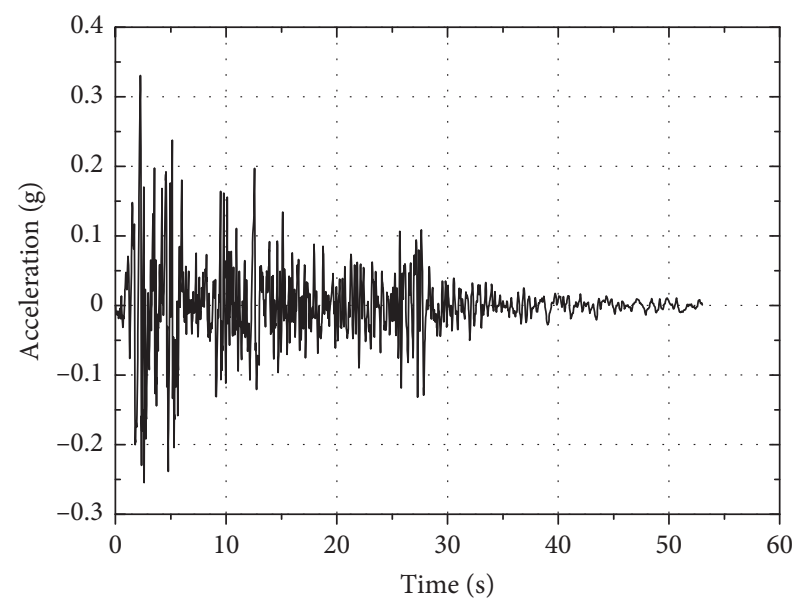

(a)

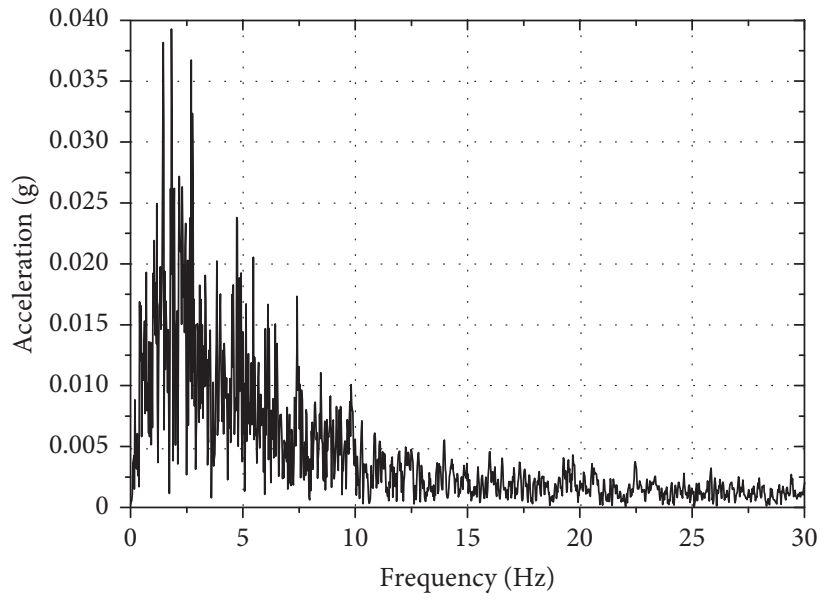

(b)

FIgURe 7: Acceleration time history and Fourier spectrum of El Centro earthquake wave.

TABLE 3: Test cases.

\begin{tabular}{lccc}
\hline Test sequence & Test no. & Input wave & PGA (g) \\
\hline 1 & WN-1 & White noise & 0.1 \\
2 & El-x0.125 & El Centro & 0.125 \\
3 & WN-2 & White noise & 0.1 \\
4 & El-x0.25 & El Centro & 0.25 \\
5 & WN-3 & White noise & 0.1 \\
6 & El-x0.375 & El Centro & 0.375 \\
7 & WN-4 & White noise & 0.1 \\
8 & El-x0.5 & El Centro & 0.5 \\
9 & WN-5 & White noise & 0.1 \\
10 & El-x0.75 & El Centro & 0.75 \\
11 & WN-6 & White noise & 0.1 \\
\hline
\end{tabular}

To control the outcomes of the shaking table test, a numerical model consistent with the experimental conditions is established by the dynamic analysis module of Midas NX (Figure 8), mainly focusing on amplification factor, interaction between soil and structure, and structural strain. The elements of soil and structure are modeled as solid elements and shell elements, respectively. The maximum sizes of soil and structure elements are set as $0.1 \mathrm{~m}$ and $0.05 \mathrm{~m}$ after the Boolean operation and matching of nodes. The constitutive model of soil is set as the linear extended Drucker-Prager model, and the linear elasticity model is utilized to consider the material of the structure; values of parameters are shown in Table 4. To simulate the contact effect of soil and utility tunnel, the master-slave surfaces are utilized with $70 \%$ of the static friction coefficient. Finally, the earthquake waves utilized in different cases of the shake table test (Table 3) are taken as the input seismic load in the numerical simulation.

\section{Test Result and Analysis}

4.1. Boundary Effect. Boundary effect is mainly caused by the rigid walls of the soil container; although the absorbing material has been considered in the design of the soil container, the difference between the model box boundary and real condition cannot be eliminated. Chen et al. [16] suggested that the boundary effect can be quantified by an index based on the 2-norm deviation. The index $\mu$ can be calculated by following equation:

$$
\mu_{x, y}=\frac{\left\|X_{i}-X_{0}\right\|}{\left\|X_{0}\right\|}
$$

where the $X_{0}$ is the peak acceleration of the reference sensor and $X_{i}$ is the corresponding acceleration of the target sensor. 

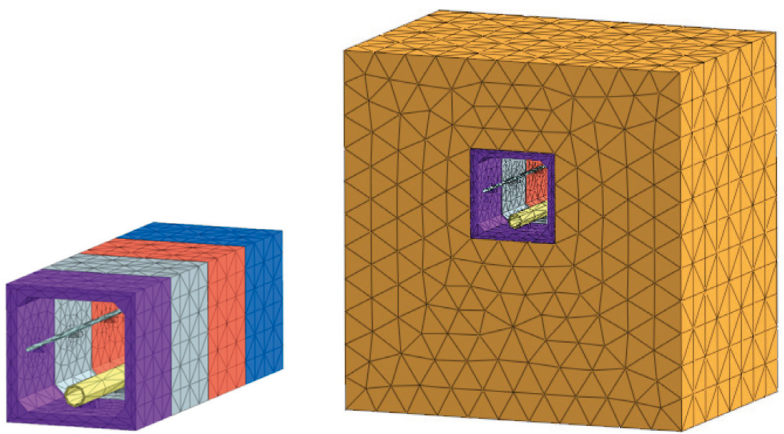

Figure 8: Numerical simulation model of the shaking table test.

TABLE 4: Material parameter of soil and structure.

\begin{tabular}{lccccc}
\hline & Density $\left(\mathrm{kN} / \mathrm{m}^{3}\right)$ & Elastic modulus $(\mathrm{MPa})$ & Poisson's ratio & Cohesion strength $(\mathrm{kPa})$ & Friction angle $\left(^{\circ}\right)$ \\
\hline Soil & 16.2 & 15.56 & 0.4 & 17.68 & 14.60 \\
Structure & 22 & 25000 & 0.18 & - & - \\
\hline
\end{tabular}

Both $X_{0}$ and $X_{i}$ can be determined from the time history in the test.

To analyse the boundary effect of model soil, the response of sensor A2 $(0.15 \mathrm{~m}$ below the tunnel bottom) and sensor A3 ( $0.15 \mathrm{~m}$ above the top of the tunnel) is taken as the references $\left(X_{0}\right)$ in calculation, respectively. Results of the calculation are indicated in Table 5, and the relationship between the index of boundary effect and input PGA is indicated in Figure 9. It can be found that (1) the index $\mu$ is in the range of $0.16 \%$ to $10.55 \%$, compared with the index $\mu$ in other shaking table tests with the similar condition $[16,18]$, and the boundary effect in this test is smaller and acceptable; (2) comparing the indexes of the shallow part and deep part of model soil, the index $\mu$ in the shallow area $\left(\mu_{3-13}\right.$ and $\left.\mu_{3-14}\right)$ is larger than that of the deep position $\left(\mu_{2-5}\right.$ and $\left.\mu_{2-6}\right)$; the maximum difference is $6.2 \%\left(\mu_{3-1}-\mu_{2-6}\right)$ when the input PGA reaches to $0.375 \mathrm{~g}$. It indicates that the boundary effect in the shallow part of model soil is relatively prominent; (3) the value of index $\mu$ generally became significant with increasing of input peak acceleration in the first three cases $(0.125 \mathrm{~g}-$ $0.375 \mathrm{~g}$ ). After that, the index $\mu$ became lower with higher input PGA ( $>0.375 \mathrm{~g}$ ), which indicates that the development of plastic deformation of soil near the boundary of the soil container can induce the boundary effect to some extent.

4.2. Acceleration Response. To investigate the dynamic response of the structure-soil system, the time histories and Fourier spectrum of surrounding soil (A9), model utility tunnel (As2), and pipeline (As6) in the test case with $\mathrm{PGA}=0.75 \mathrm{~g}$ are indicated in Figure 10. There is no significant delay between the acceleration response of soil and structure; amplitude of the model tunnel is slightly smaller than the surrounding soil. Note that the peak acceleration of the pipeline on side wall of the tunnel is much larger than the model tunnel. As for spectrum, it can be found that the spectrum of the utility tunnel and surrounding soil is similar; the first and second predominant frequencies are prominent, around $6.1 \mathrm{~Hz}$ and $26 \mathrm{~Hz}$, respectively. The predominant
TABLE 5: Index of boundary effect in the shaking table test.

\begin{tabular}{lccccccc}
\hline \multicolumn{2}{c}{ Input PGA } & $0.125 \mathrm{~g}$ & $0.25 \mathrm{~g}$ & $0.375 \mathrm{~g}$ & $0.5 \mathrm{~g}$ & $0.75 \mathrm{~g}$ \\
\hline \multirow{4}{*}{ Index } & Shallow & $\mu_{3-13}$ & 0.16 & 5.46 & 9.94 & 4.56 & 0.68 \\
$\mu(\%)$ & part & $\mu_{3-14}$ & 0.26 & 5.96 & 10.55 & 4.28 & 0.17 \\
& \multirow{2}{*}{ Deep part } & $\mu_{2-5}$ & 2.46 & 3.26 & 3.80 & 2.54 & 3.73 \\
& & $\mu_{2-6}$ & 1.51 & 2.36 & 4.35 & 0.63 & 1.24 \\
\hline
\end{tabular}

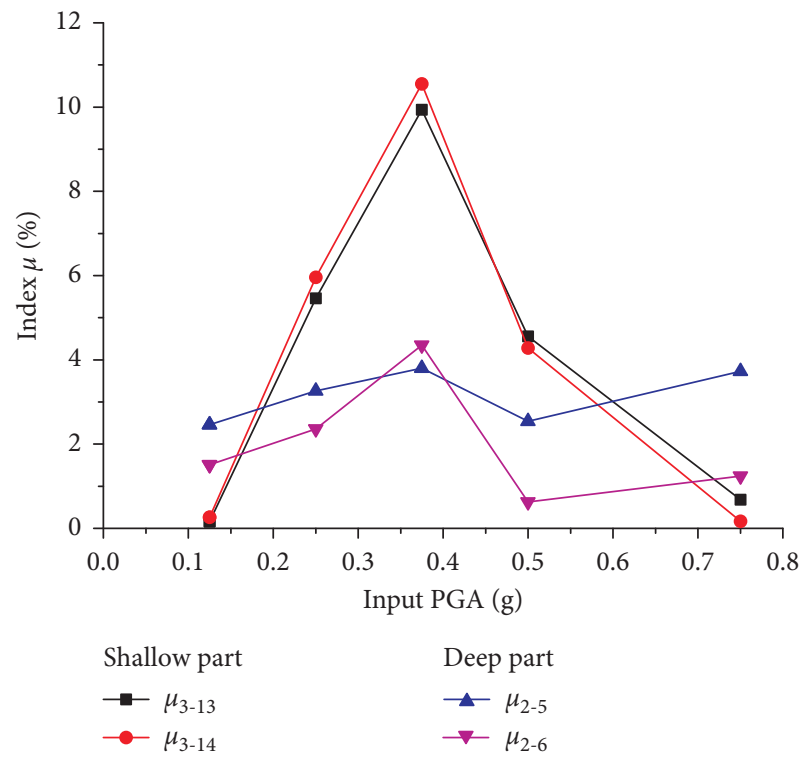

Figure 9: Relationship between index $\mu$ and input PGA.

frequency of the pipeline is around $36 \mathrm{~Hz}$ singly. More specific analysis and the evolution of the predominant frequencies are indicated in Section 4.3.

4.3. Amplification Factor. To investigate the acceleration amplification effect of model soil under different input PGA, the ratio of peak acceleration value of A1, A2, A7, A9, A11, 


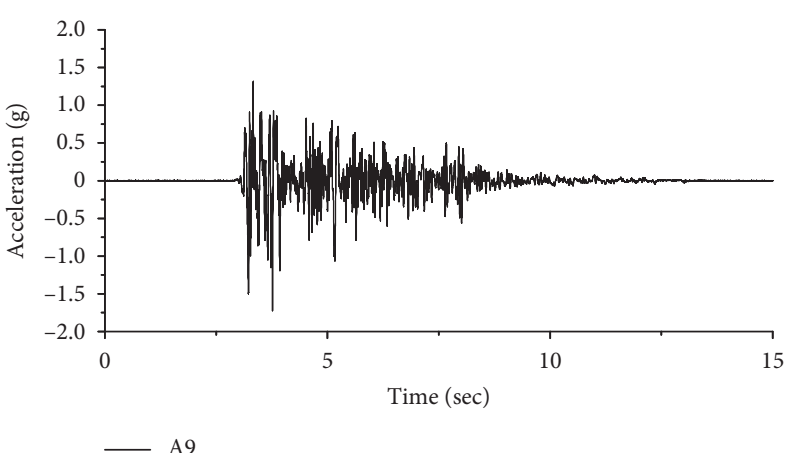

(a)

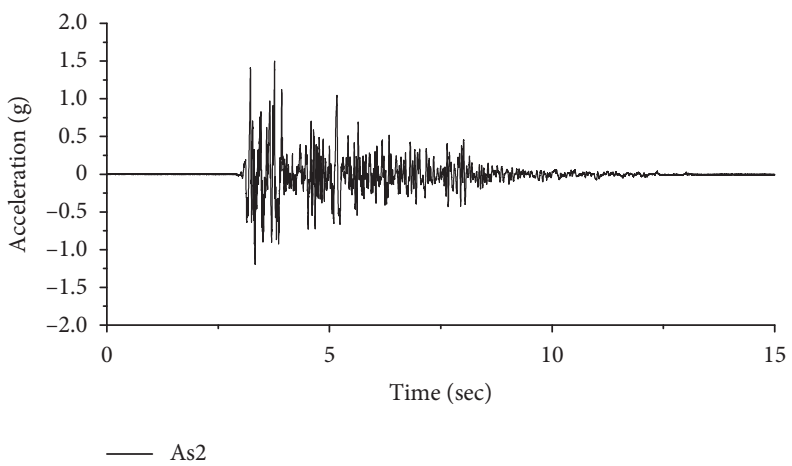

(c)

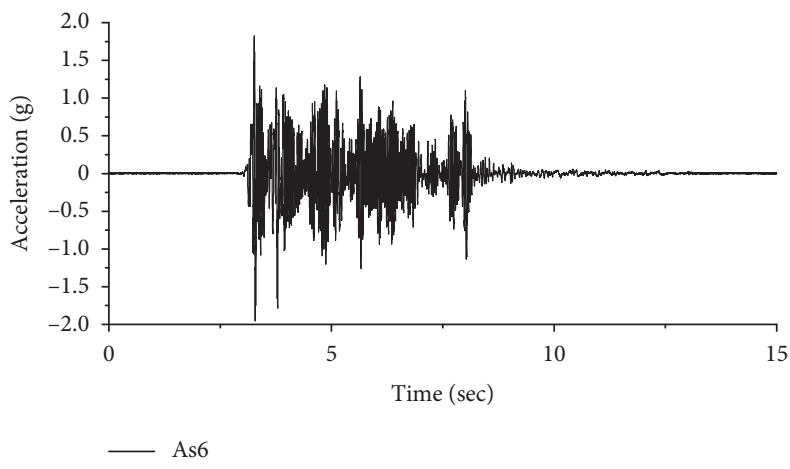

(e)

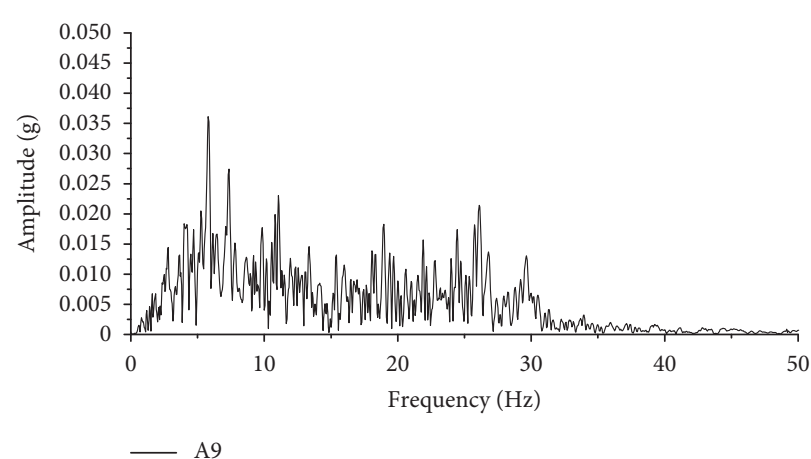

(b)

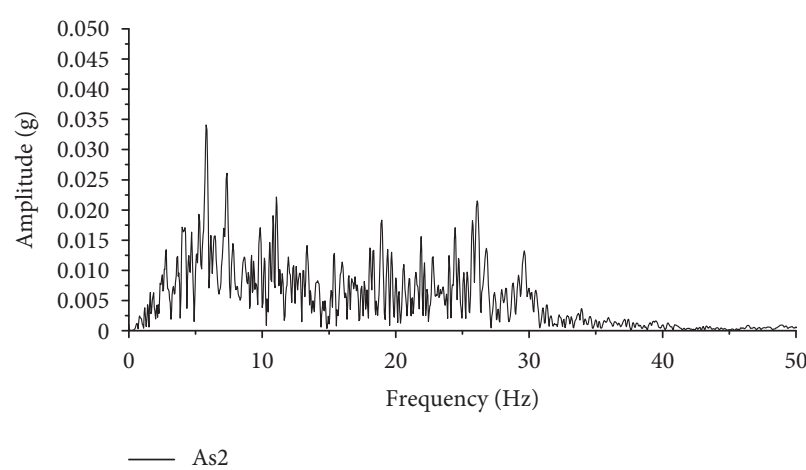

(d)

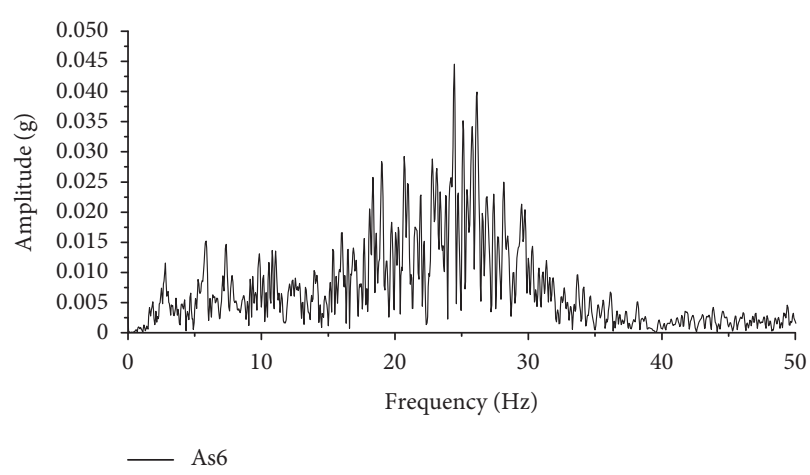

(f)

FiguRe 10: Dynamic responses of horizontal acceleration and Fourier spectra in the case of $0.75 \mathrm{~g}$. (a, b) A9 of model soil. (c, d) As2 on the model tunnel. (e, f) As6 on the model tunnel.

A3, and A4 to the peak value of ACC on the shaking table (A0) is set as the amplification factor of soil in this test. As shown in Figure 11, it can be found that, for the lowest input wave $(\mathrm{PGA}=0.125 \mathrm{~g})$, the value of amplification factor increases from the bottom to the top of the model soil, the maximum value is up to 2.5. With the increase of input PGA, the amplification factor generally decreases. With input PGA increasing from $0.375 \mathrm{~g}$ to $0.75 \mathrm{~g}$, the maximum acceleration amplification factor of soil decreases from 1.8 to 1.38 . Note that when input PGA reaches to $0.75 \mathrm{~g}$, the amplification factor of soil around the utility tunnel is relatively prominent ( $0.4 \mathrm{~m}$ to $0.85 \mathrm{~m}$ from the bottom of the soil container). In numerical simulation, the amplification factor decreases from 2.6 to 1.4 with the seismic load increasing from $0.125 \mathrm{~g}$ to $0.75 \mathrm{~g}$, the peak values and distributions are well consistent with those of the shaking table test.

To explore the amplification effect of the utility tunnel and the pipelines inside, the ratio of peak acceleration value of As1, As2 (installed on side wall of the utility tunnel) and As6, As7 (installed on pipelines inside) to the peak value of As3 (on the bottom of the utility tunnel) is set as the structural amplification factor, as shown in Figure 12. From Figure 12(a), it can be found that the amplification factor along the side wall generally increases from the bottom to the top. In the initial case ( $0.125 \mathrm{~g}$ input), the amplification factor at the top (As3) is around 1.18. With increasing of input PGA $(0.25 \mathrm{~g}$ to $0.5 \mathrm{~g})$, the maximum factor decreases to 1.12 . When the input PGA reaches to $0.75 \mathrm{~g}$, the 


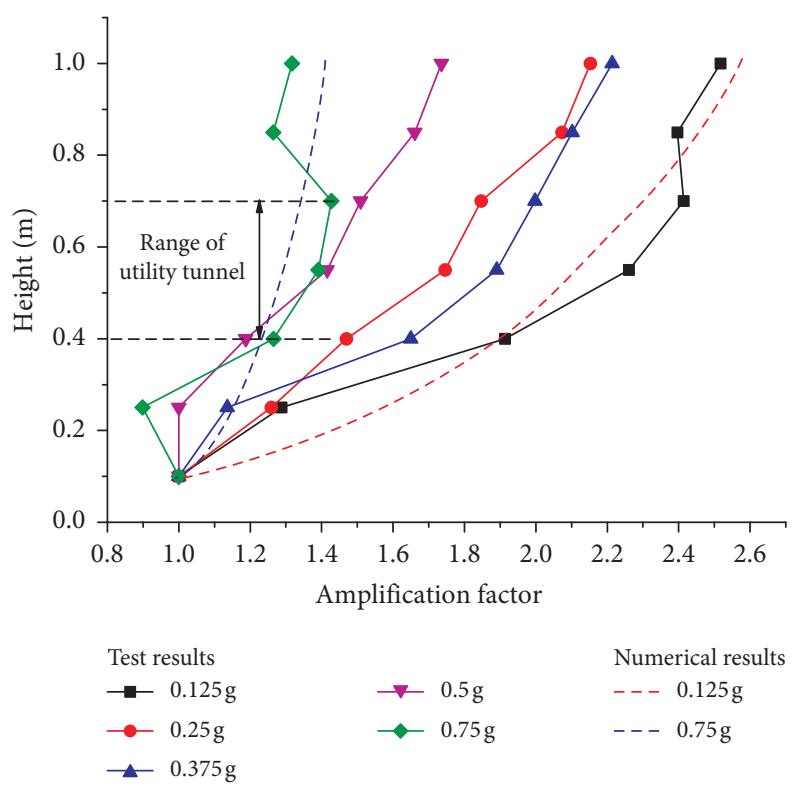

Figure 11: Acceleration amplification factors of model soil.

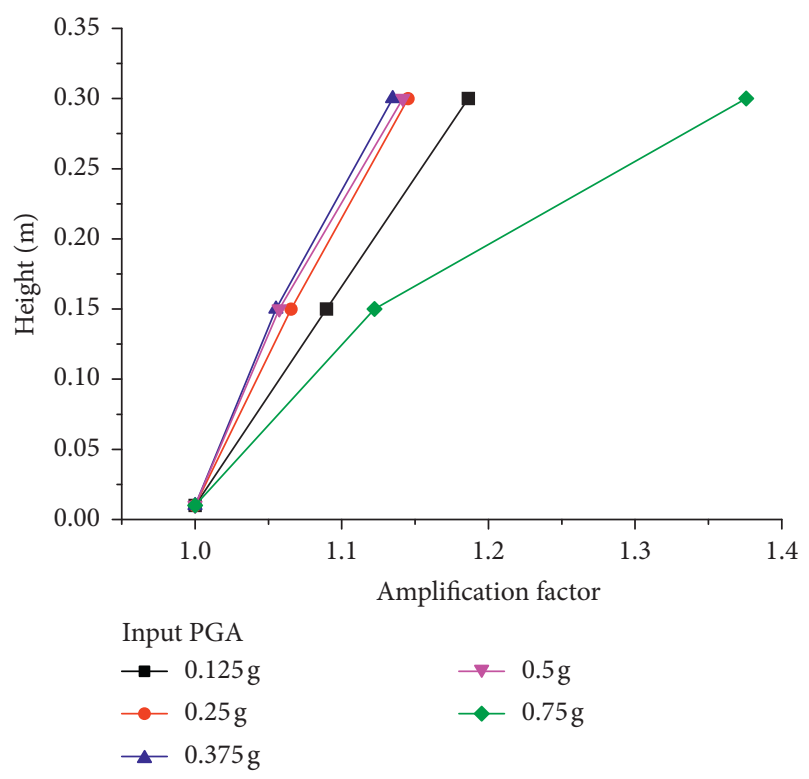

(a)

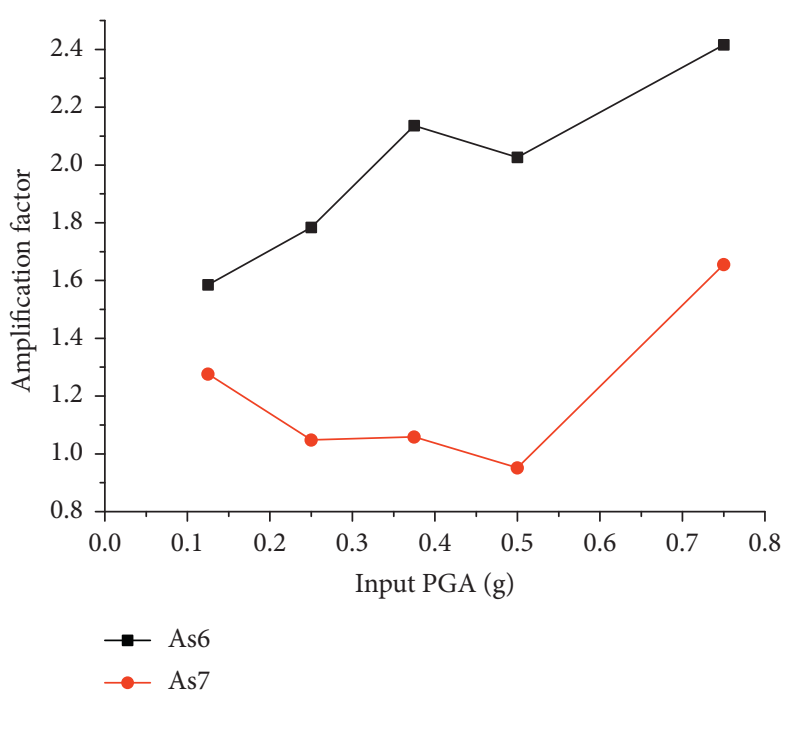

(b)

FIgURE 12: Acceleration amplification factor of the structure: (a) model tunnel and (b) pipelines hold by the tunnel.

maximum amplification factor rapidly increases to 1.38 . Moreover, some cracks around the corner of the utility tunnel were observed, which is related to the rapid increase of the amplification factor. For the pipelines installed in the utility tunnel, from Figure 12(b), it can be found that the amplification factor of the pipeline on the side wall (As6) increases from 1.58 to 2.41 with the input PGA rising from $0.125 \mathrm{~g}$ to $0.75 \mathrm{~g}$. Generally, the amplification factor of the pipeline on the floor (As7) is much smaller. With input PGA rising from $0.125 \mathrm{~g}$ to $0.5 \mathrm{~g}$, the amplification factor of As7 decreases from 1.27 to 0.95 slowly. When the input PGA increases to $0.75 \mathrm{~g}$, the amplification factor of As7 rapidly increases to 1.6 with the observation of the failure of the pipe rack.

4.4. Fourier Spectra. In order to explore the evolution of predominant frequencies of the soil-structure system, the predominant frequencies of soil, structural model, and pipelines under different input PGA are given in Table 6. The relationship between predominant frequencies of soil and the corresponding depth is shown in Figure 13. By comparing the Fourier spectra of sensors A1, A2, A7, A9, A11, $\mathrm{A} 3$, and $\mathrm{A} 4$ with the same distance in the vertical direction, it 
Table 6: Predominant frequencies of soil and structure.

\begin{tabular}{|c|c|c|c|c|c|c|c|c|c|c|}
\hline & \multicolumn{8}{|c|}{ Soil } & \multirow{3}{*}{$\begin{array}{c}\text { Utility tunnel } \\
\text { As2 }\end{array}$} & \multirow{3}{*}{$\frac{\text { Pipeline }}{\text { As6 }}$} \\
\hline \multirow{2}{*}{\multicolumn{2}{|c|}{$\begin{array}{l}\text { Distance from the } \\
\text { bottom }(\mathrm{m})\end{array}$}} & A1 & $\mathrm{A} 2$ & A7 & A9 & A11 & $\mathrm{A} 3$ & $\mathrm{~A} 4$ & & \\
\hline & & 0.1 & 0.25 & 0.4 & 0.55 & 0.7 & 0.85 & 1 & & \\
\hline \multirow{3}{*}{ Input PGA } & $0.125 \mathrm{~g}$ & 7.300 & 25.698 & 29.599 & 29.649 & 29.699 & 25.748 & 25.748 & 25.748 & 25.649 \\
\hline & $0.375 \mathrm{~g}$ & 5.833 & 5.833 & 26.050 & 26.100 & 29.650 & 29.651 & 29.650 & 26.1 & 25.2 \\
\hline & $0.75 \mathrm{~g}$ & 5.838 & 5.838 & 5.800 & 5.800 & 5.800 & 26.124 & 26.099 & 26.049 & 18.9 \\
\hline
\end{tabular}

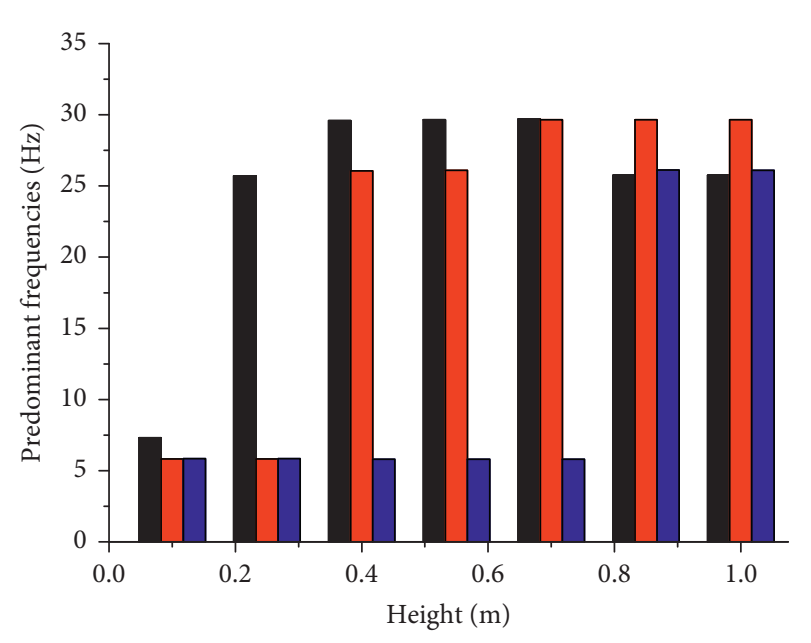

Input PGA

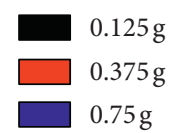

FIgURE 13: Predominant frequencies of soil at different positions.

is found that low frequency was amplified from the bottom to the top of model soil with the input PGA increasing gradually. For instance, in the case of $0.125 \mathrm{~g}$, the first predominant frequencies of soil at different depths are in the range of $25 \mathrm{~Hz}$ to $30 \mathrm{~Hz}$. When input PGA increases to $0.75 \mathrm{~g}$, the first predominant frequencies of soil have nearly all decreased to $5.8 \mathrm{~Hz}$, except for the most shallow position.

From Table 6, it can also be found that the predominant frequencies of the model tunnel are similar to those of model soil due to the constraint of the surrounding soil, and they are also related to the amplitude of input PGA. As shown in Figure 14(a), the first predominant frequency of the model tunnel gradually decreases from $26.65 \mathrm{~Hz}$ to $25.18 \mathrm{~Hz}$ and decreases by $5 \%$; the second predominant frequency decreases from $7.29 \mathrm{~Hz}$ to $5.84 \mathrm{~Hz}$ and decreases by $19 \%$. The main reason for this phenomenon is that the overall stiffness of the structural model is continuously decreasing with various seismic vibrations, which is similar to the result of the buried tunnel [19]. Cracks on the model tunnel and model soil observed during the test are indicated in Section 4.5. For pipelines installed inside of the utility tunnel, the first predominant frequencies of pipelines (As6 and As7) are indicated in Figure 14(b). Note that with the increasing of input PGA, the first predominant frequency of the pipeline on the side wall of the tunnel gradually decreases from $29.59 \mathrm{~Hz}$ to $26.1 \mathrm{~Hz}$ and decreases by $11.9 \%$; the first predominant frequency of the pipeline on the tunnel floor decreases from $29.6 \mathrm{~Hz}$ to $18.9 \mathrm{~Hz}$ and decreases by $36.15 \%$, with the failure of pipe rack.

4.5. Interaction between Soil and Structure. As shown in Figure 15(a), the distribution of dynamic soil pressure under different input PGA is recorded by sensors S1, S2, S3, S5, and S6. And, the results from numerical simulation are represented by dotted lines. It can be found that the soil pressure generally increases with the rise of input PGA, and the pressure of soil around the structure is relatively larger than other locations in each case. When PGA $>0.375 \mathrm{~g}$, the growth rate of soil pressure around the utility tunnel increases obviously; the concentrated soil pressure around the underground utility tunnel would induce to the seismic damage. Furthermore, Figure 15(b) shows the interaction between surrounding soil and the model tunnel. It can be found that the horizontal interaction between the model structure and the surrounding soil is not uniform. For lower input PGA $(\leq 0.375 \mathrm{~g})$, the soil pressure on the top of the side wall is slightly larger than lower locations. When the input PGA exceeds $0.375 \mathrm{~g}$, the interaction increases rapidly and takes a triangle distribution, approximately. The pressure on the upper part of the side wall is larger, and it can be inferred that the shear deformation around the utility tunnel appears with the trend of rotation of the cross section. The numerical simulation results show similar regularity with the smoother curve due to the more dense monitor points.

4.6. Structural Strain. During the shaking table test, the dynamic strain of the utility tunnel was recorded by FBG sensors, and the results of numerical simulation also provide comparable reference. The distributions of the peak strain in each case along the cross section $(\mathrm{F} 1-\mathrm{F} 8)$ and the longitudinal direction (F9-F15) are depicted in Figures 16(a) and 16(b), respectively. From Figure 16(a), it can be found that the strain of the tunnel model generally increases with the rising of input PGA. With input PGA increasing from $0.12 \mathrm{~g}$ to $0.5 \mathrm{~g}$, the strain around the middle of the side wall rises obviously (between F1 and F7), the maximum strain reaches to $43.3 \mu \varepsilon$ (at F5). When the input PGA increases from $0.5 \mathrm{~g}$ to $0.75 \mathrm{~g}$, the maximum strain appears at the bottom corner (F2), and the strain of sensor F6 at the top corner is the secondary peak. The values of the maximum strain at above corners are $101.6 \mu \varepsilon$ and $68.3 \mu \varepsilon$. Aforementioned results are in-line with the numerical simulation and damage observation in this test (seen in Section 4.6).

Furthermore, the distribution of longitudinal strain of the utility tunnel is indicated in Figure 16(b). It is found that 


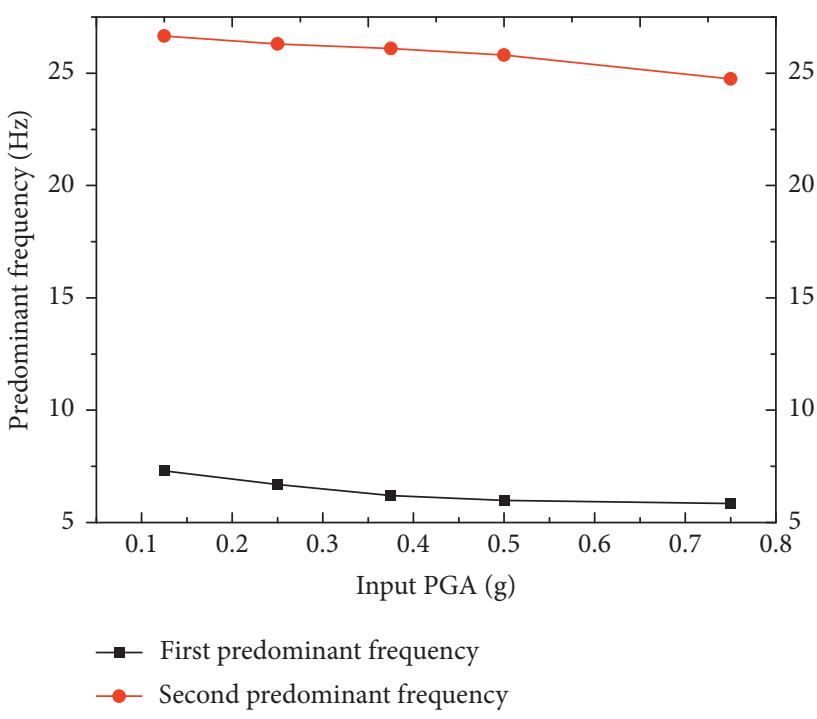

(a)

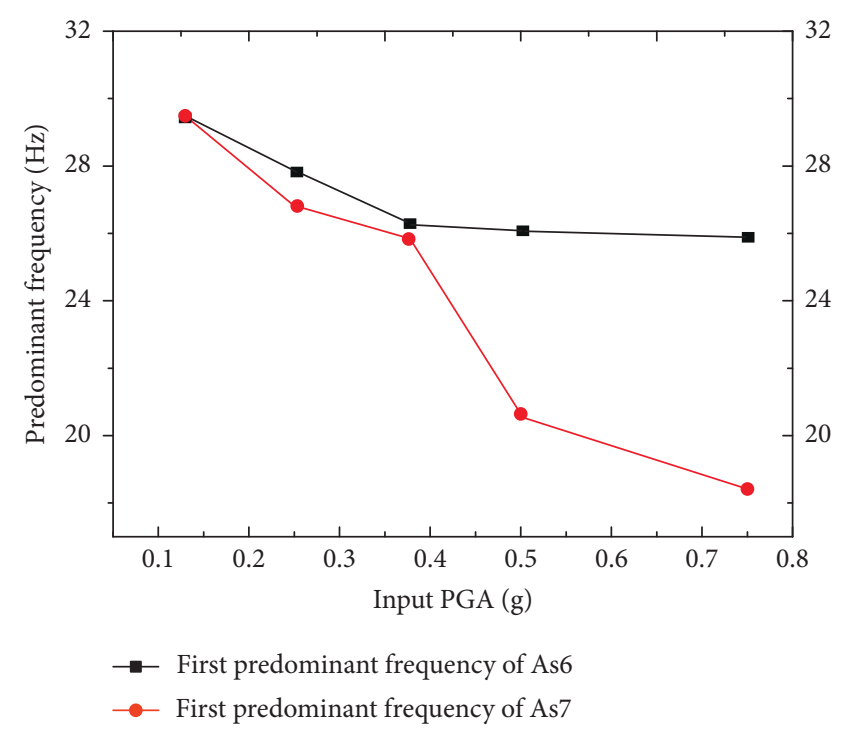

(b)

FIGURE 14: Evolution of predominant frequencies of the utility tunnel (a) and pipelines inside (b).

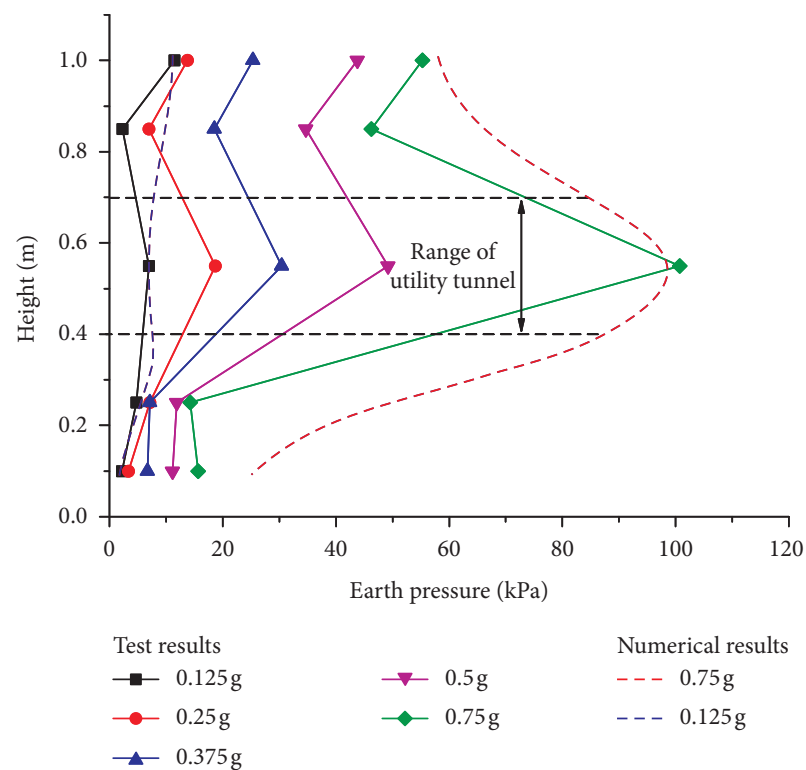

(a)

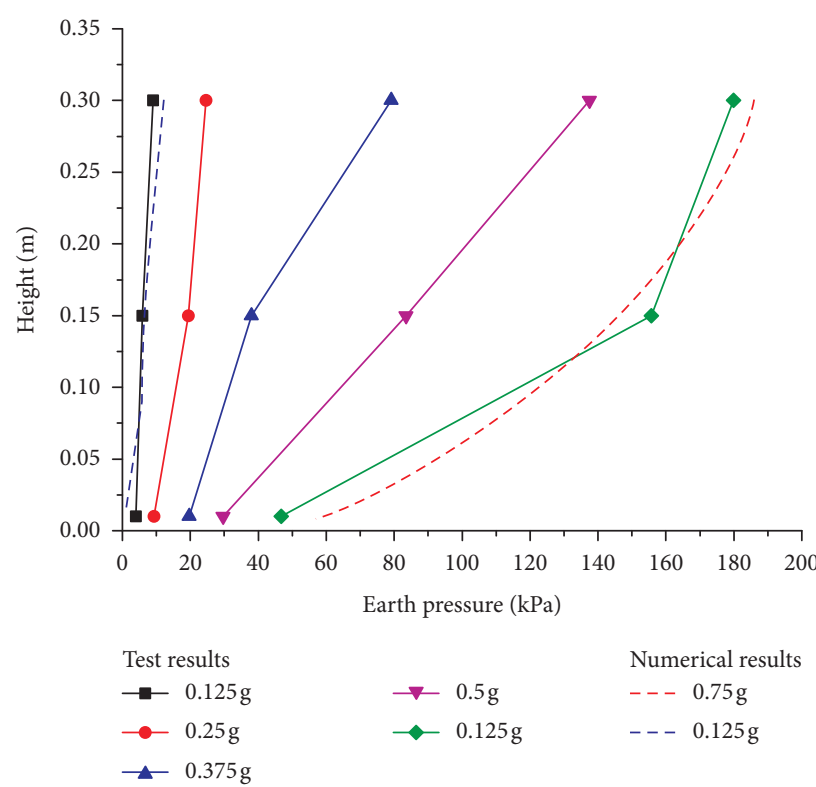

(b)

FIgURE 15: Distribution of maximum soil pressure (a) and the pressure on the soil-structure interface (b).

the strain of the tunnel near the joint is relative larger than that of the middle position of the segment, and the difference is directly proportional to the amplitude of input PGA. For instance, the maximum strain of F11 is 15\% larger than F10 with $0.125 \mathrm{~g}$ excitation, and it reaches to $29 \%$ with $0.75 \mathrm{~g}$ excitation. The outcomes from numerical simulation are similar, and the corresponding values are $19 \%$ and $27 \%$. This observation indicates that the joints of the prefabricated utility tunnel would bear extra axial force during earthquake. In horizontal earthquake, the axial force of the utility tunnel mainly comes from the relative rotation and displacement of adjacent segments. When the relative movement of segments is distinctly large, pullout cracking and failure may occur near the joints which need to be paid attention in seismic design.

4.7. Damage Phenomenon. During the shaking table test, the damage phenomena are observed as indicated in Figure 17. Several cracks occurred around the top and bottom corners, as shown in Figures 17(a) and 17(b); the locations are consistent with the distribution of structural strain. These 

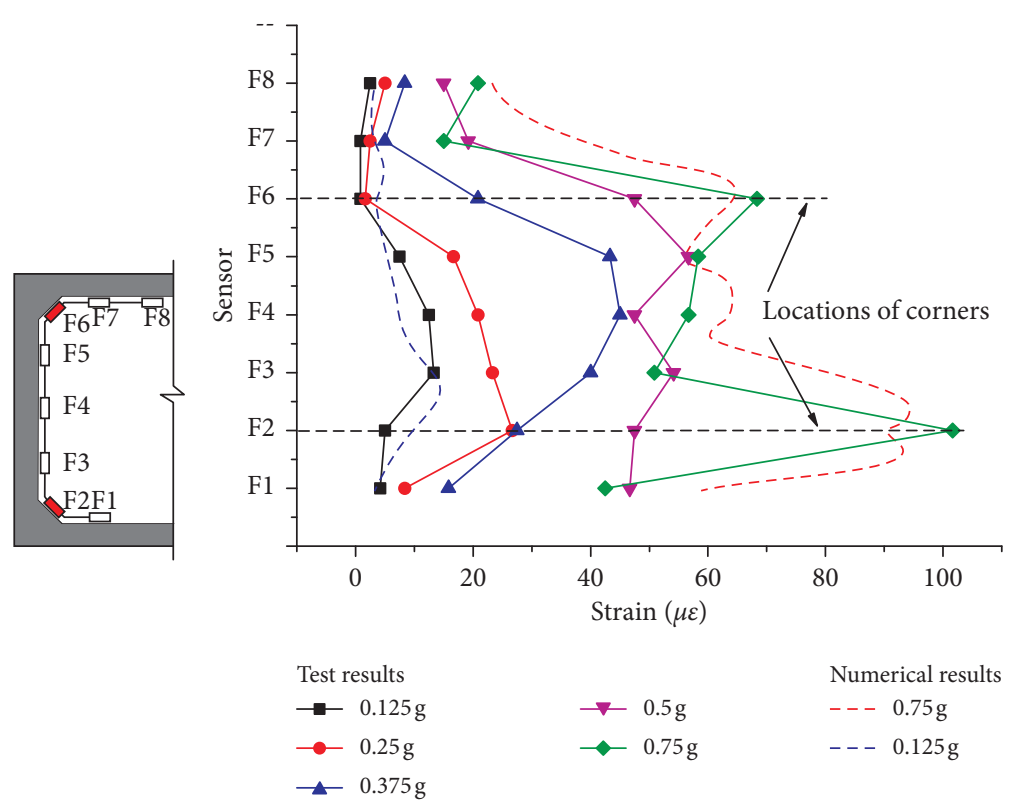

(a)
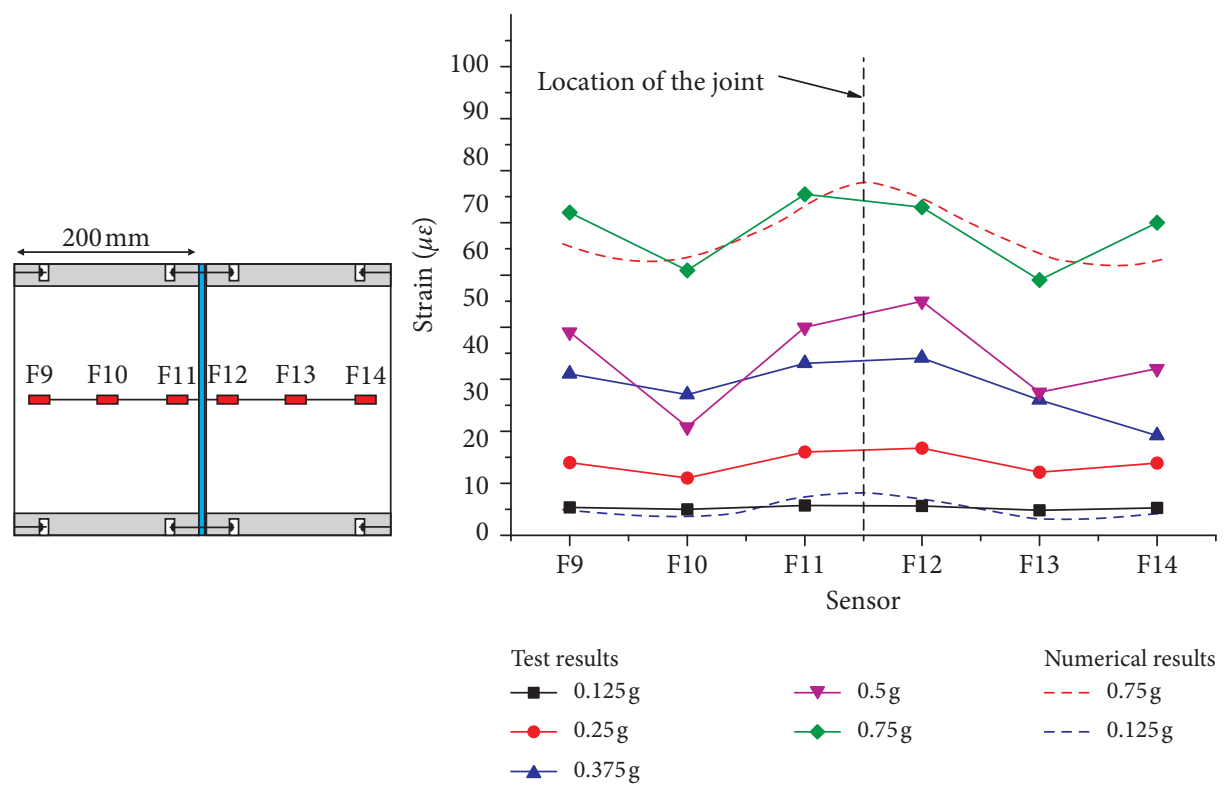

(b)

Figure 16: Distribution of structural strain of the utility tunnel: (a) along the cross section; (b) longitudinal strain.

structural cracks are generally perpendicular to the walls with the length of $30 \mathrm{~mm}$. In addition, as shown in Figure 17 (c), the longitudinal cracks are observed on the outer side of the tunnel model, and they are coherent with the cracks shown in Figures 16(a) and 16(b). Furthermore, the cracks around the pipeline rack were observed when the input PGA $>0.375 \mathrm{~g}$, at the same time, the predominant frequencies of pipelines started to decrease. Up to the input PGA reaching to $0.75 \mathrm{~g}$, the rack of the gas pipe model was completely destroyed; the pipeline was removed from the floor of the utility tunnel, as shown in Figure 17(d). As previous analysis of its Fourier spectra, decrease of the predominant frequency is related to the development of the seismic damage. Furthermore, the shear stress on the pipe rack installed on the tunnel floor exceeds its limit in horizontal earthquake.

\section{Conclusion}

In this paper, a series of shaking table tests have been conducted to investigate the seismic performance of the prefabricated utility tunnel, including acceleration, dynamic soil pressure, and structural strain are analyzed. Additionally, results of numerical simulation have been utilized to verify the outcomes of the shaking table test. The findings are given as follows: 


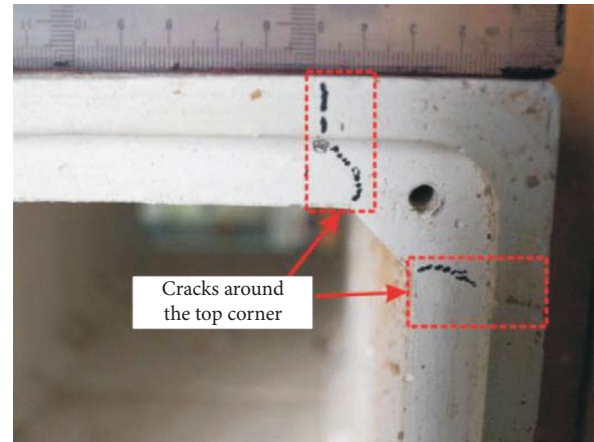

(a)

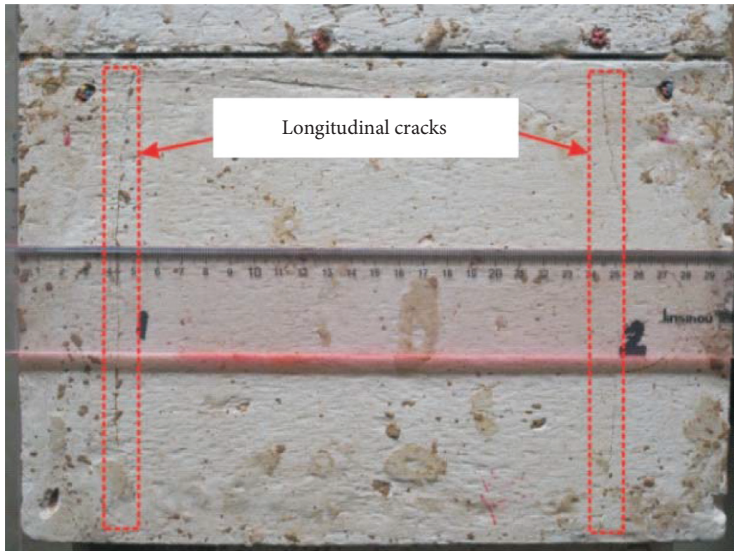

(c)

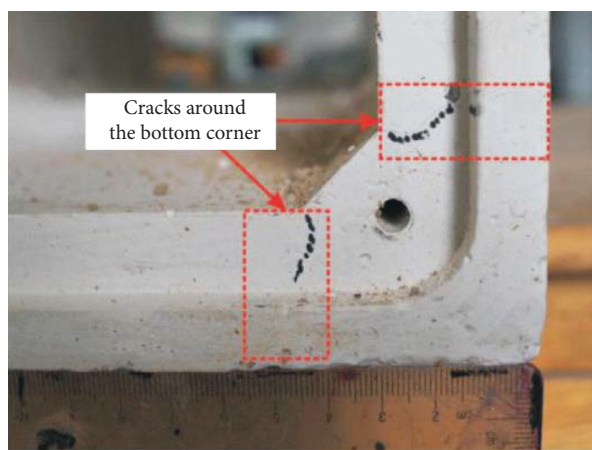

(b)

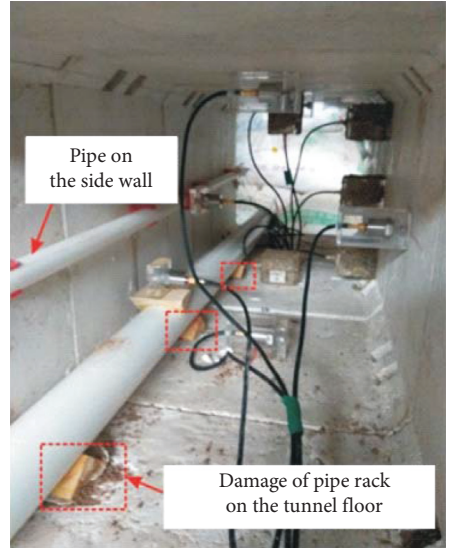

(d)

Figure 17: Damage phenomena in the test. (a-c) Cracks on the model structure. (a) Cracks around the top corner. (b) Cracks around the bottom corner. (c) Longitudinal cracks. (d) Damage of pipeline rack.

(1) Through the evaluation by the 2-norm index, the boundary effect of the model ground is related to depth. The boundary effect in the shallow part of the model ground is more obvious than deeper positions. The maximum value of the boundary index reaches to $10.55 \%$; it demonstrates that the soil container used in this test does not impose significant boundary effect.

(2) Effect of acceleration amplification in loess foundation is observed in shaking table tests. The PGA increased with the height of the site, and it has great influence on the acceleration response of the shallow-buried utility tunnel. Due to the constraint of surrounding soil, amplification effect is also observed on the side wall of the utility tunnel.

(3) The acceleration response of the pipelines hold by the utility tunnel is observed larger than the tunnel structure, and the decrease of the predominant frequency is found to be a sign before the failure of pipeline. In the tests, the rack of the pipe model on the floor was failure with an input PGA of $0.75 \mathrm{~g}$; it is suggested that the shock absorption of pipelines inside of the utility tunnel should be considered in seismic design, especially for the pipes with high weight and rigidity.
(4) The critical positions of the prefabricated utility tunnel during earthquake have been released during the tests. The dynamic strain concentrates around the top and bottom corners of the cross section, and longitudinal strain near the joints is $29 \%$ larger than that of the middle position of the segment with $0.75 \mathrm{~g}$ excitation. The observation of structural cracks verifies the results.

\section{Data Availability}

The data used to support the findings of this study are available from the corresponding author upon request.

\section{Conflicts of Interest}

The authors declare that they have no conflicts of interest.

\section{Acknowledgments}

The authors gratefully acknowledge the financial support from the National Natural Science Foundation of China (grant no. 41902299 and 41672305), the Key Science and Technology Program of Shaanxi Province (grant no. 2017ZDXM-SF-078), and the Shaanxi New-Star Plan of Science and Technology (grant no. 2018KJXX-020). 


\section{References}

[1] W. J. Boegly JR. and W. L. Griffith, "Underground utility tunnels," Mechanical Engineering, vol. 93, no. 9, pp. 27-32, 1971.

[2] J. L. He, X. J. Zhang, X. Y. Ma, and H. Hao, "The organization and ensurence of general survey for urban underground pipeline," Urban Development Studies, vol. 20, no. 3, pp. 108-112, 2013, in Chinese.

[3] W. C. Xue, H. D. Wang, and X. Hu, "Economic analysis of PPMT in shanghai expo area," Special Structure, vol. 26, no. 2, pp. 101-104, 2009, in Chinese.

[4] Y. Chang, X. Li, E. Masanet, L. Zhang, Z. Huang, and R. Ries, "Unlocking the green opportunity for prefabricated buildings and construction in China," Resources, Conservation and Recycling, vol. 139, pp. 259-261, 2018.

[5] J. Hong, G. Q. Shen, Z. Li, B. Zhang, and W. Zhang, "Barriers to promoting prefabricated construction in China: a costbenefit analysis," Journal of Cleaner Production, vol. 172, pp. 649-660, 2018.

[6] Y. M. A. Hashash, J. J. Hook, B. Schmidt, and J. I.- Chiang Yao, "Seismic design and analysis of underground structures," Tunnelling and Underground Space Technology, vol. 16, no. 4, pp. 247-293, 2001.

[7] A. J. Schiff, "Hyogoken-Nanbu (Kobe) earthquake of January 17, 1995 lifeline performance," in Technical Council on Lifeline Earthquake Engineering Monograph, No. 14, ASCE, Reston, VI, USA, 1998.

[8] JCSE, Investigation Report on Hyogoken Nambu EarthquakeAnalysis of Civil Structure Damage, Chapter 5: Tunnel and Underground Structure, Japan Society of Civil Engineer, Tokyo, Japan, 1999, in Japanese.

[9] PWRI, "Damage analysis and seismic performance assessment of utility tunnel in Hogoken-Nambu earthquake," Report No. 3821, Public Works Research Institute, Tsukuba, Japan, 2001, in Japanese.

[10] T. Nishioka and S. Unjoh, "A simplified evaluation method for the seismic performance of common utility boxes with rectangular cross section," Journal of Structure Engineering, vol. 48, pp. 1461-1468, 2002.

[11] G. Nakanura, K. Kawashima, and G. Watanabe, "Evaluation on seismic retrofit measures for common utility tunnels based on cyclic loading tests," Proceeding of Civil Engineering Institute, vol. 62, no. 3, pp. 489-508, 2006, in Japanese.

[12] J. Li, Q. X. Yue, and J. Chen, "Research on shaking-table test and finite element numerical simulation of utility tunnel," Journal of Earthquake Engineering and Engineering Vibration, vol. 29, no. 4, pp. 41-45, 2009.

[13] G. Tsinidis, "Response characteristics of rectangular tunnels in soft soil subjected to transversal ground shaking," Tunnelling and Underground Space Technology, vol. 62, no. 1, pp. 1-22, 2017.

[14] A. P. Tang, Z. Q. Li, R. C. Feng, and C. Y. Zhou, "Model experiment and analysis on seismic response of utility tunnel systems using a shaking table," Journal of Harbin Institute of Technology, vol. 41, no. 6, pp. 1-5, 2009, in Chinese.

[15] Q. X. Yue and J. Li, "Research on utility tunnel seismic response," Journal of Tongji University (Natural Science), vol. 37, no. 3, pp. 285-290, 2009, in Chinese.

[16] J. Chen, X. Shi, and J. Li, "Shaking table test of utility tunnel under non-uniform earthquake wave excitation," Soil Dynamics and Earthquake Engineering, vol. 30, no. 11, pp. 1400-1416, 2010.
[17] D. Lombardi, S. Bhattacharya, F. Scarpa, and M. Bianchi, "Dynamic response of a geotechnical rigid model container with absorbing boundaries," Soil Dynamics and Earthquake Engineering, vol. 69, pp. 46-56, 2015.

[18] G. X. Chen, H. Y. Zhuang, and X. L. Du, "Analysis of largescale shaking table test of dynamic soil-subway station interaction," Earthquake Engineering and Engineering Vibration, vol. 27, no. 2, pp. 171-176, 2007.

[19] F. Wang, X. Jiang, J. Niu, and H. Yang, "Experimental study on seismic dynamic characteristics of shallow-bias tunnel with a small space," Shock and Vibration, vol. 2018, Article ID 6412841, 9 pages, 2018. 


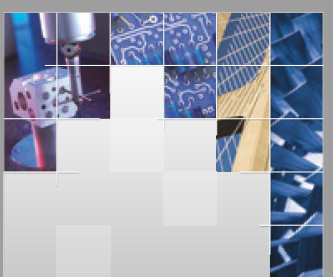

\section{Enfincering}
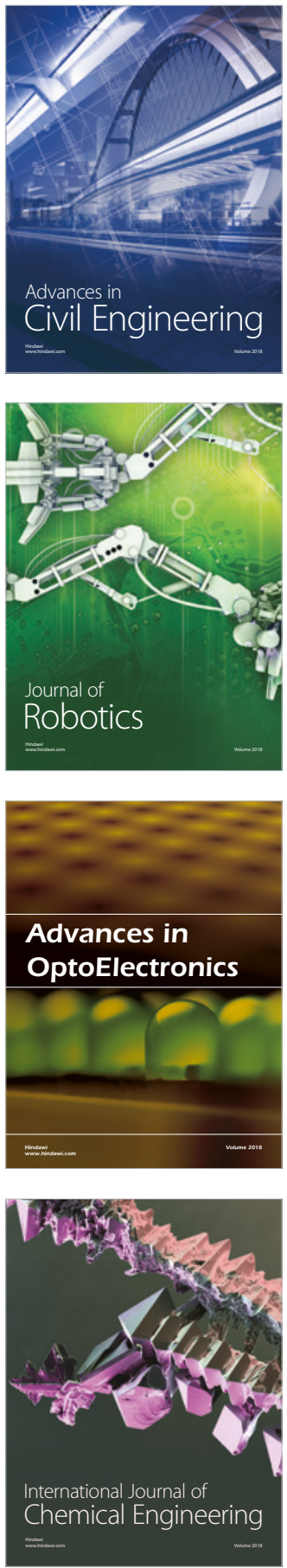

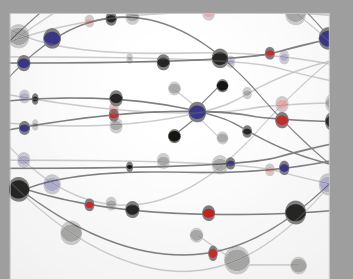

\section{Rotating \\ Machinery}

The Scientific World Journal

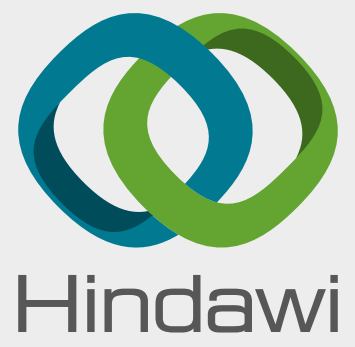

Submit your manuscripts at

www.hindawi.com
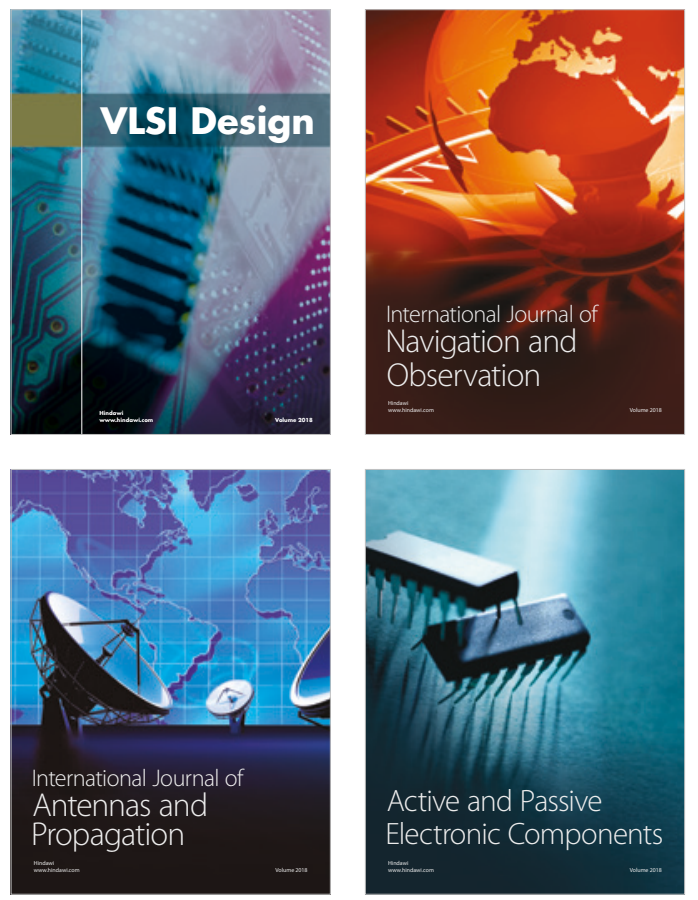
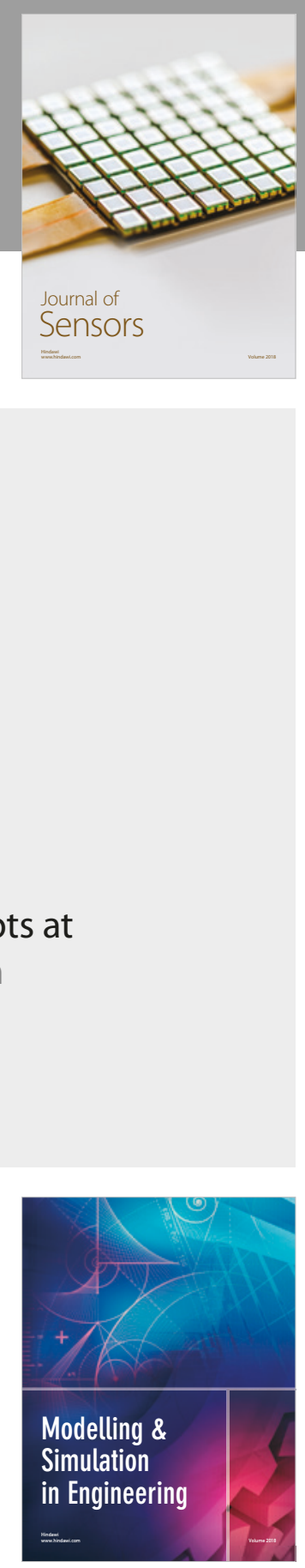

\section{Advances \\ Multimedia}
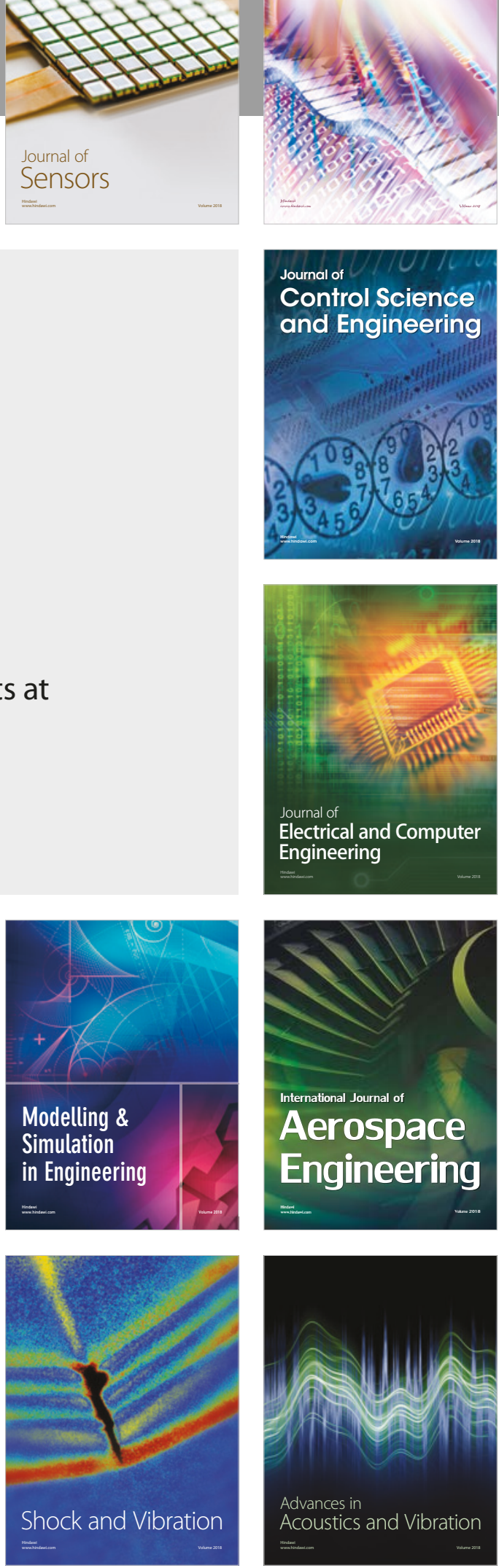